\title{
Digital Video Watermarking for Copyright Labelling
}

\author{
Fitria Ilhami Ikromina \\ Information Technology Study Program Magister Program \\ of Technnology University of Yogyakarta \\ Yogyakarta, Indonesia \\ Email: Ikromina1996 [AT] gmail.com
}

\author{
Erik Iman Heri Ujianto \\ Information Technology Study Program \\ Magister Program of Technology University of Yogyakarta \\ Yogyakarta, Indonesia \\ Email: Erik.iman [AT] uty.ac.id
}

Abstract---The use of multimedia content in the internet is now growing, especially in digital video. Counterfeit, fraud, and plundering of video content cause problem because of resource supply for sharing contents. Copyright becomes crusial matter in digital video to avoid manipulation of the irresponsible ones. There are many ways to do for labelling copyright into a video. One of them is digital watermarking. Digital watermaking is used to prevent illegal replication or exploitation of digital content, protect digital content, and avoid multimedia manipulation illegally. The use of several methods such as Discrete Wavelet Transform (DWT), Discrete Cosine Transform (DCT), and Discrete Fourier Transform (DFT) for labelling copyright of video will be compared based on the imperceptibility and robustness after several manipulations applied into inserted-watermark video. From the point of imperceptibility, DWT method results PSNR value at 45, 62435 dB, DCT method results PSNR value at $45,89422 \mathrm{~dB}$, and DFT method results PSNR value at 45, 77747 dB. The PSNR mean from these three methods is $45,76535 \mathrm{~dB}$. It means that the insertedwatermark video appears similiar to the intercalated one. Thus, from the experiment, it can be sum up that the implemented DWT, DCT, and DFT method show that the watermarked video still in a good quality that it is reasonable and meets the imperceptibility. From the point of robustness, the NC mean of DCT method is 0,63974 , DCT method is 0,755839 , and DFT method is $\mathbf{0 , 7 4 5 4 4 2}$. It tells that the result of watermark extraction from these three methods is the same as the original watermark. In other word, all of the watermarks on these three methods can be well extracted though the attacks are delivered to them. From the level of imperceptibility and robustness test on DWT, DCT, and DFT method, it can be said that DCT method is better than DWT and DFT method because it performs a high value on PSNR and NC.

Keywords-Digital Watermarking; DWT; DCT; DFT, PSNR; NC

\section{INTRODUCTION}

In this rapid era of technology, internet becomes one of information sources for people [1]. With the development of multimedia and internet, digital distribution and transmission are getting easier. The use of multimedia content is growing in the internet, especially digital video. Today, counterfeit, fraud, and plundering of video content cause problem. The technology of video is one of important technologies in multimedia communication in which the video provides information that completes other media such as image, text, and voice. The benefit of technology has been applied in application on several fields such as education, health, entertainment, bussiness, infromation, etc. It becomes new challenges to protect video distribution. Today, the protection of digital multimedia is very important because the resource supply for sharing contents illegally such as video, music, audio, and image [2]. Now, safety becomes one of important parts because it is related to the copyright of digital content to guarantee the ownership identification.

Copyright becomes crusial matter in digital video to avoid manipulation of the irresponsible ones. There are many ways to do for protecting copyright on distribution of electronic and multimedia information and publication by internet. One of techniques which can be used to protect copyright of digital video is watermarking [4] [5]. According to [6] the information can be in the form of digital image, audio, or video. In multimedia platform, digital watermarking becomes efficient technology in protecting data of digital video [7]. Digital watermarking is used to prevent illegal replication or exploitation of digital content and avoid the multimedia manipulation illegally [8].Digital watermarking refers to insertion in multimedia document and file continually to protect them from illegal copying and identifies manipulation [9]. Watermarking technique used colored image as copyright protection from video and watermarking color which is implemented into video in invisible form. Invisible watermarking is a kind of technology which can solve the problem of copyright [4]. Ownership identification and hidden information use several methods such as Discrete Wavelet Transform (DWT), Discrete Cosine Transform (DCT), Discrete Fourier Transform (DFT). The researcher will 
compare these three methods based on imperceptibility and robustness after several manipulation applied into insertedwatermark video.

\section{RELATED WORKS}

According to [10] watermark using Transformasi Wavelet Diskrit (TWD) had a quite good quality because the image of insertion inside the video was not visually seen. But after the extraction, the inserted image could be identified and the PNSR value was quite good with the maximal value almost at $30 \mathrm{~dB}$. The calculation of PNSR showed that the original video and the watermrked video are almost similiar so that it visually could not be differentiated. Based on [11] DFT method is resist toward attacks like cropping, resize and editing, and also it produced a low value of changing percentage on NPCR and UACI testing. It reached a high value on PSNR testing as well.

Based on [12] by using DWT, DCT, and SS method, the result of system testing using layer blue, sub band LL, mother wavelet $\mathrm{dB}$ and the measurement rate of $80 \%$ had average PNSR value at $86,9216 \mathrm{~dB}$, MSE value at 27,39059667 and BER value at 0,162519 . The system could endure well toward attack of Noise Gaussian Blur. According to [7] the proposed DWT technique showed a high efficiency and was proved that it was able to endure toward several attacks like Gaussian, salt and pepper, rotation, frame dropping, cropping and averaging. The proposed technique also showed a high imperceptibility in which there was no visual degradation seen inside the video clip after the watermark implemented and extracted with avarage PNSR, all watermarks frame were 57.3118. There was no quality decline on PNSR which was marked by watermark.

According to [8] DWT was used as the domain of insertion or watermark extraction. The firm of this technique wsd tested by implementing any kinds of attacks such as geometrix, noise, compression format, and attack of image processing. The result of simulation showed the effectiviy and good performance and also could save the system resource, memory capacity, and bandwith of communication. Based on \{13] the main benefit of DWT and DCT method were strong and resist toward any kinds of attacks such as image cropping, rotation, Gussian noise, salt and pepper noise, poison's noise, speckle noise with implementation of result showed that the inserted video was really good with high PSNR.

Based on [4] the performance analysis of invisible watermaking could be measured by comparing Mean Square Error (MSE) dan PNSR because each of them implanted and extracted image. Based on Nagajyothi and KrJain (2020) the analysis was shown by different matrix such as PNSR to measure the transparant effect with value of $160,7011 \mathrm{~dB}$ Besides, the other matrixes such as MSE and NCC were to describe the watermark quality with similiar measurement. The MSE value for proposed approach was 0,0068 and 1 for NCC which proved that the watermark was free from attacks.

According to [14] the proposed system might cause watermarking by using DCT which had a higher embedding capacitity and gave a better result with a high accuracy. The framework was based on Hartung technique which was dependend on spectrum spread communication in DCT. The result of the experiment considered several JPEG-compression approaches, geometric distortion and noise. The result showed a good performance toward the proposed method, the provided technique not oly for MPEG-2 video but also for coding video DCT and many others such as MPEG-1, H261 and H 26[15].

According to [1] the research selected DCT as the method because this method was firmer toward image manipulation, especially the compression. The watermark insertion is conducted toward high frequency of coefisien of DCT. The JPEG compression testing toward the watermarked image produced watermarked image which resist toward compression until $50 \%$ and resulted a quite high PNSR value of $30 \mathrm{~dB}$. The testing in the form of screen capture resulted watermark image in low quality with avarage PNSR value at $25 \mathrm{~dB}$. In the testing of image in the form of cropping, the watermark image will disappear in the cropped area. The testing in the form of color changing and text addition produced watermark image extraction with a good quality of imperceptibility. However, the watermark image had a low value of PSNR because its value was under $30 \mathrm{~dB}$. But in the background changing and filter addition in the form of emboss and blur filter, it produced an extraction of poor watermark image. It was because of poor PSNR value or the value was under $15 \mathrm{~dB}$.

\section{RESEARCH METHODS}

This research will be done through several steps as follows:

\section{A. Collecting Literature}

It aims at collecting complete literature about the topic observed. Collecting the literature is conducted by searching books, journals, and thesis related to the topic observed. Based on the collected materials, it is then conducted the developing toward watermarking algorithm which will be observed.

\section{B. Analyzing and Designing Software}

At this step, flowchart is arranged based on algorithm which will be improved. The arragement of flowchart aims at easing the software arrangement. The analyzis can also be done by creating Data Flow Diagram (DFD) of improved software. The arrangement is made by creating face-to-face design between software and the arrangement of procedures which will be used.

\section{Arranging Software}

The result of flowchart design then is implemented using Matlab R2013a. The arrangement of software goes through process of embedding, attacking, and extracting.

\section{Testing of Software}

The arraged software is then tested using the data of the selected video. At this step, the testing is conducted to identify whether the software has already worked as it is planned. And a revision can be conducted if it is out of the plan. 


\section{Variable}

The data which will be used in this research are a video and image.

\section{E. Method of Analyzing}

There are three main processes: process of embedding, attacking, and extracting.

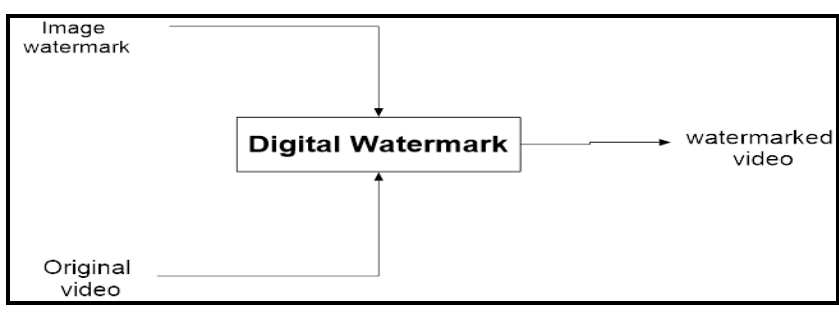

Figure 1 . Embedding Process

In the embedding process, the image of watermark appears as image in the form of copyright message which will be inserted inside a video and the original video as the original video which will be inserted with copyright message. Image of watermark and original video which are included into digital watermark system results watermarked video in which the video contains watermark in the form of image.

\begin{tabular}{|c|c|c|}
\hline $\begin{array}{l}\text { Watermarked } \\
\text { video }\end{array}$ & Attacks & $\begin{array}{c}\text { Attacked } \\
\text { watermarked } \\
\text { video }\end{array}$ \\
\hline
\end{tabular}

Figure 2. Attacking Process

In the attacking process, attacks are added to the alreadywatermarked video in order to result the already-watermarked video which has been added with attacks to analyze the influence of attacks toward video.

\begin{tabular}{|c|c|c|}
\hline $\begin{array}{c}\text { Attacked } \\
\text { Watermarked } \\
\text { video }\end{array}$ & $\begin{array}{c}\text { Watermark } \\
\text { Detection }\end{array}$ & - $\begin{array}{c}\text { Image } \\
\text { Watermark }\end{array}$ \\
\hline
\end{tabular}

Figure 3. Extracting Process

In the extracting process, the watermark of watermarked video which contains attacks is described to identify the influence of attacks toward watermark image.

\section{FINDINGS AND DISCUSSION}

In the testing of video watermarking program with Discrete Wavelet Transform (DWT), Discrete Cosine Transform (DCT), Discrete Fourier Transform (DFT) method, it is used a mp4 extended video host as can be seen in Figure. 4. The video host used as testing sample is a mp4 video host. Figure.5 is the image used as the image of watermark which has jpg. extention.

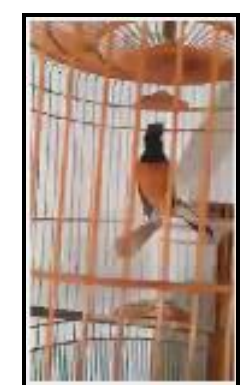

Figure 4. Video Host

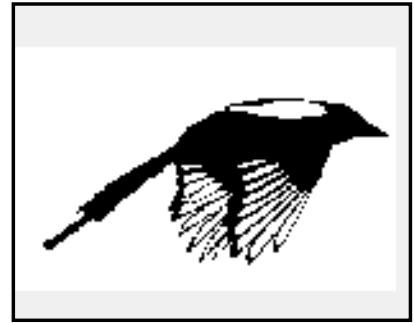

Figure 5. Image of watermark
After the watermark insertion in the video host is done and the watermarked video is obtained, then it is followed by two kinds of testing, imperceptibility and robustness testing.

\section{A. Testing in Imperceptibility Level}

The inserted watermark should not damage the quality of video host. To understand the influence of watermark insertion toward the quality of video host, Peak Signal Noise Ratio (PNSR) is used in the imperceptibility testing.

PSNR uses a logaritmic scale with decibel to evaluate the similarity between video host and watermarked video. The higher the PNSR value, the better the quality of watermark video. The PNSR value under $30 \mathrm{~dB}$ shows a poor quality of video and it is not qualified. This following Table 1 is the result of imperceptibility testing which purposes to find out the sensitivity of human vision sensory on detecting the difference between the host and watermaked video.

TABLE 1. HASIL PENGUJIAN IMPERCEPTIBILITY MENGGUNAKAN PSNR RESULT OF IMPERCEPTIBILITY TESTING USING PNSR

\begin{tabular}{|c|c|}
\hline PSNR RESULT OF IMPERCEPTIBILITY TESTING USING PNSR \\
\hline METHOD & PSNR \\
\hline Discrete Wavelet Transform (DWT) & $45,62435 \mathrm{~dB}$ \\
\hline Discrete Cosine Transform (DCT) & $45,89422 \mathrm{~dB}$ \\
\hline Discrete Fourier Transform ( DFT) & $45,77747 \mathrm{~dB}$ \\
\hline
\end{tabular}

Based on the result of imperceptibility testing, DWT method has PSNR value at 45, $62345 \mathrm{~dB}$, DCT method results PSNR value at $45,89422 \mathrm{~dB}$, and DFT method gets PSNR value at $45,77747 \mathrm{~dB}$. From these three methods, the mean of PNSR value is $45,76535 \mathrm{~dB}$ which means that the insertedwatermark video visually seems similar to the intercalated one. Thus, from this testing, it can be concluded that the implemented DWT, DCT, and DFT method show that the watermarked video is still in the reasonable quality and meets the imperceptibility factor. 
TABLE 2. RESULT OF WATERMARK INSERTION INTO HOST VIDEO

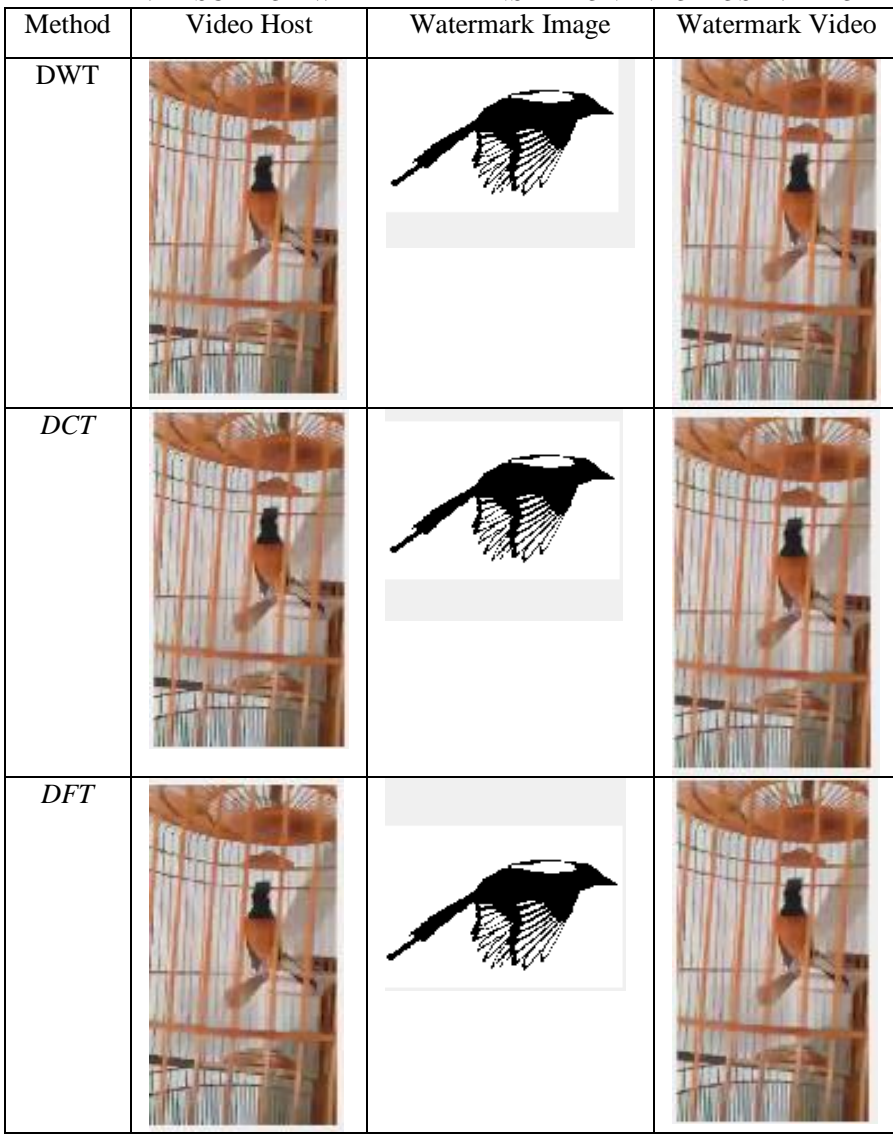

The result shown in the Table 2 is the video host which has been inserted with watermark image. Visually, it is similiar to the orginal video host. Besides, the inserted watermark does not appear (invisible). It means that the inserted watermark is well stored and does not damage the video quality. The detected PSNR value can also prove that the method used in this research has a good level of imperceptibility.

\section{B. Testing in Robustness Level}

Robustness testing aims at detecting the resistance level of watermark when it is added by several attacks -in the form of digital image processing- which try to delete or throw the watermark away from the watermark video. The resistance can be detected from how high the possibility of watermark can be called back during the extracting process. To find out the possibility, Normalized Correction (NC) is used to count it. $\mathrm{NC}$ value is reached by extracting the watermark from the watermarked video. NC indicates the similarity of watermark before and after the attacks are added on it. It also can be mentioned as the level of watermark extraction. The higher the $\mathrm{NC}$ value, the more similiar the original watermark and the attacked one. NC value is in the range of 0 and 1.0 value means that the attacked watermark has no similarity at all to the original one. In contrast, 1 value tells that both of the compared images are exactly similiar.
In this robustness experiment, the previous attacks are applied in this watermark image. The applied attacks is in the form of digital image such as speckle noise, Gaussian noise, histogram equalization, contrast adjustment, salt and pepper noise, poison noise, framing dropping, frame swapping, frame averaging, jpeg compression, resizing, rotation, gamma correction, and median filtering.

TABLE 3. RESULT OF WATERMARK INSERTION BEFORE ATTACK DELIVERING

\begin{tabular}{|l|c|}
\hline \multicolumn{1}{|c|}{ Method } & $\begin{array}{c}\text { NC Value of Watermark Before } \\
\text { Attacks Delivering }\end{array}$ \\
\hline Discrete Wavelet Transform (DWT) & 0,538985 \\
\hline Discrete Cosine Transform (DCT) & 0,755901 \\
\hline Discrete Fourier Transform ( DFT) & 0,751341 \\
\hline
\end{tabular}

Table 3 shows the level of reverting the watermark through DCT method is higher than through DWT and DFT. It means that extracting the watermark through DCT method is better than through DWT and DFT when the attacks are not delivered yet. The mean of watermark similarity between the original and the extracted one by these threee method is 0,682076 . It shows a good watermark reverting value. It also causes the original watermark and the extracted one quite similar.

The next step is delivering attacks to the watermarked image and counting the NC value by extracting the watermark. The NC value resulted from the robustness experiment through DWT method toward several attacks is showed in the following Table 4.

TABLE 4. RESULT OF ROBUSTNESS TES THROUGH DWT METHOD USING NC

\begin{tabular}{|c|c|}
\hline Types of Attacks & Value of Normalized Correction \\
& $(\mathrm{NC})$ \\
\hline Speckle noise & 0,75952 \\
\hline Gaussian noise & 0,67832 \\
\hline Histogram equalization & 0,51537 \\
\hline Contrast adjustment & 0,48471 \\
\hline Salt and pepper noise & 0,52503 \\
\hline Poisson noise & 0,62658 \\
\hline Frame dropping & 0,665 \\
\hline Frame swapping & 0,705 \\
\hline Frame averaging & 0,56599 \\
\hline Jpeg compression & 0,63745 \\
\hline Resizing & 0,61702 \\
\hline Rotation & 0,7193 \\
\hline Gamma correction & 0,78775 \\
\hline Median filtering & 0,66937 \\
\hline
\end{tabular}


Table 4, overall, the $\mathrm{NC}$ value is 0,63974 in avarage. It means that the result of extraction is similiar to the original one. In other word, through the DWT method, all of the watermarks can be well extracted though the attacks are delivered to them.

TABLE 5. EXTRACTION RESULT OF WATERMARKE AND FRAME OF VIDEO AFTER ATTACKS DELIVERING

\begin{tabular}{|c|c|c|}
\hline $\begin{array}{c}\text { Types of } \\
\text { Attacks }\end{array}$ & VIDEO AFTER ATTACKS DELIVERING & Frame of Video After \\
Attacks Delivering
\end{tabular}

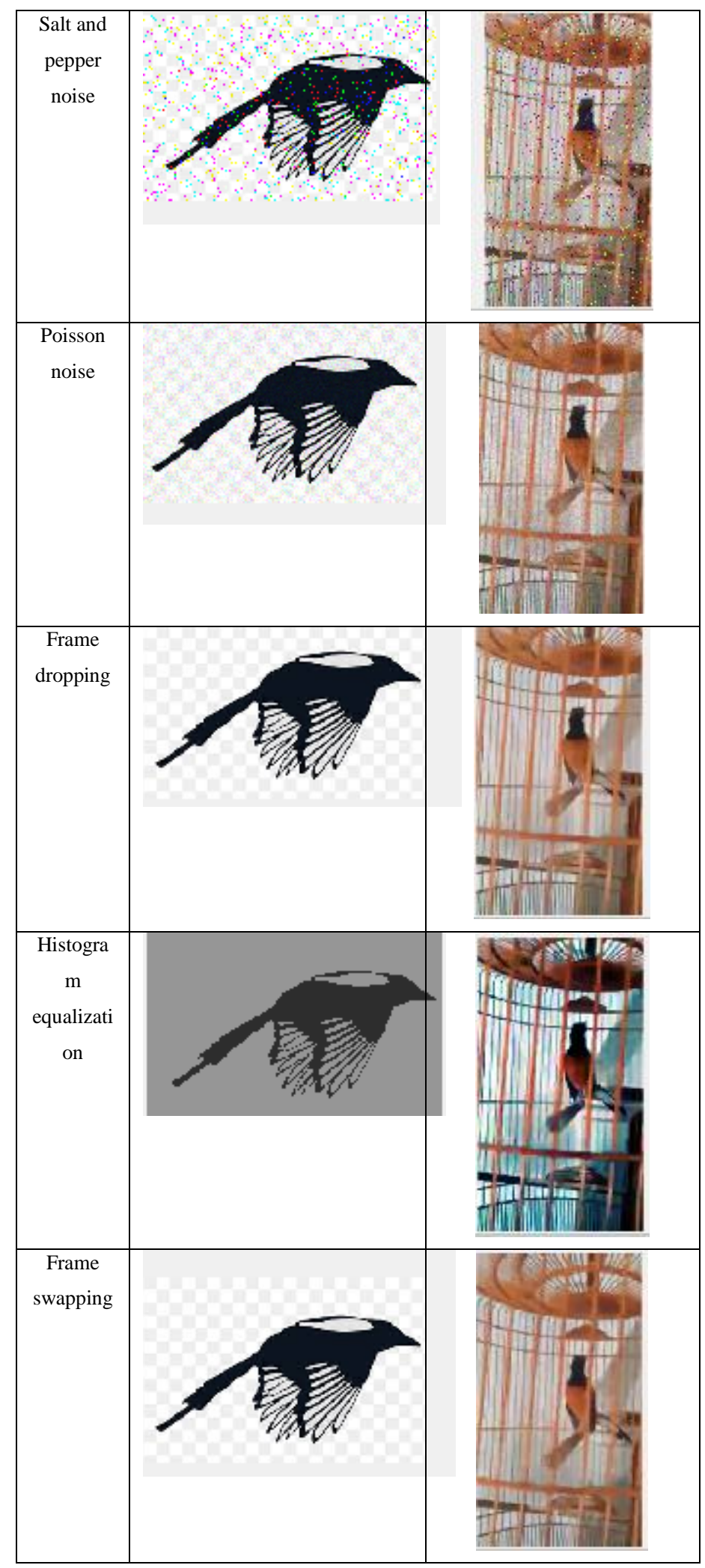



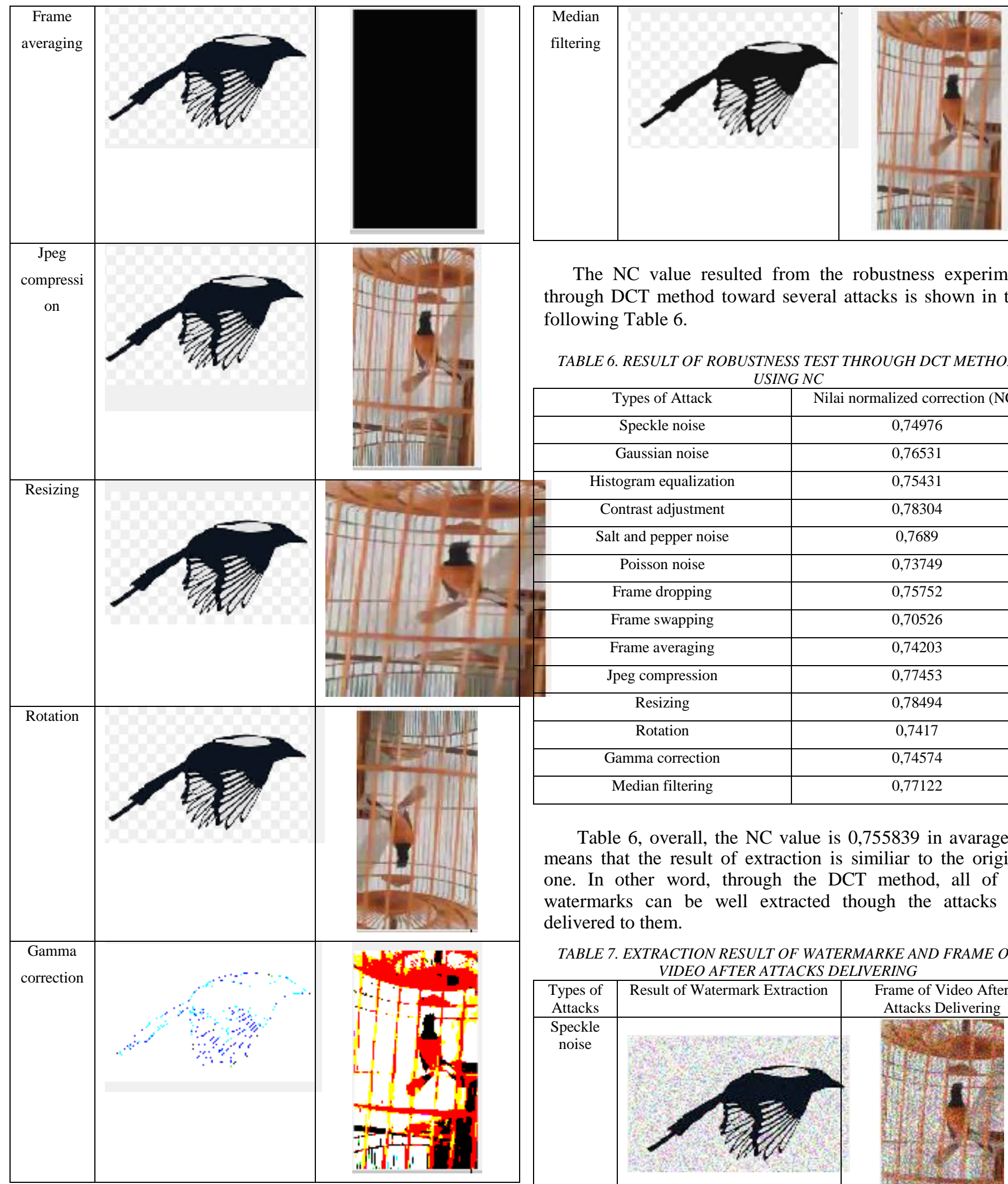

The NC value resulted from the robustness experiment through DCT method toward several attacks is shown in this following Table 6 .

\begin{tabular}{|c|c|} 
TABLE 6. RESULT OF ROBUSTNESS TEST THROUGH DCT METHOD \\
USING NC \\
\hline Types of Attack & Nilai normalized correction (NC) \\
\hline Speckle noise & 0,74976 \\
\hline Gaussian noise & 0,76531 \\
\hline Histogram equalization & 0,75431 \\
\hline Contrast adjustment & 0,78304 \\
\hline Salt and pepper noise & 0,7689 \\
\hline Poisson noise & 0,73749 \\
\hline Frame dropping & 0,75752 \\
\hline Frame swapping & 0,70526 \\
\hline Frame averaging & 0,74203 \\
\hline Jpeg compression & 0,77453 \\
\hline Resizing & 0,78494 \\
\hline Rotation & 0,7417 \\
\hline Gamma correction & 0,74574 \\
\hline Median filtering & 0,77122 \\
\hline
\end{tabular}

Table 6, overall, the NC value is 0,755839 in avarage. It means that the result of extraction is similiar to the original one. In other word, through the DCT method, all of the watermarks can be well extracted though the attacks are delivered to them.

TABLE 7. EXTRACTION RESULT OF WATERMARKE AND FRAME OF VIDEO AFTER ATTACKS DELIVERING

\begin{tabular}{|c|c|c|}
\hline $\begin{array}{c}\text { Types of } \\
\text { Attacks }\end{array}$ & Result of Watermark Extraction & $\begin{array}{c}\text { Frame of Video After } \\
\text { Attacks Delivering }\end{array}$ \\
\hline $\begin{array}{c}\text { Speckle } \\
\text { noise }\end{array}$ & & \\
& & \\
\hline
\end{tabular}



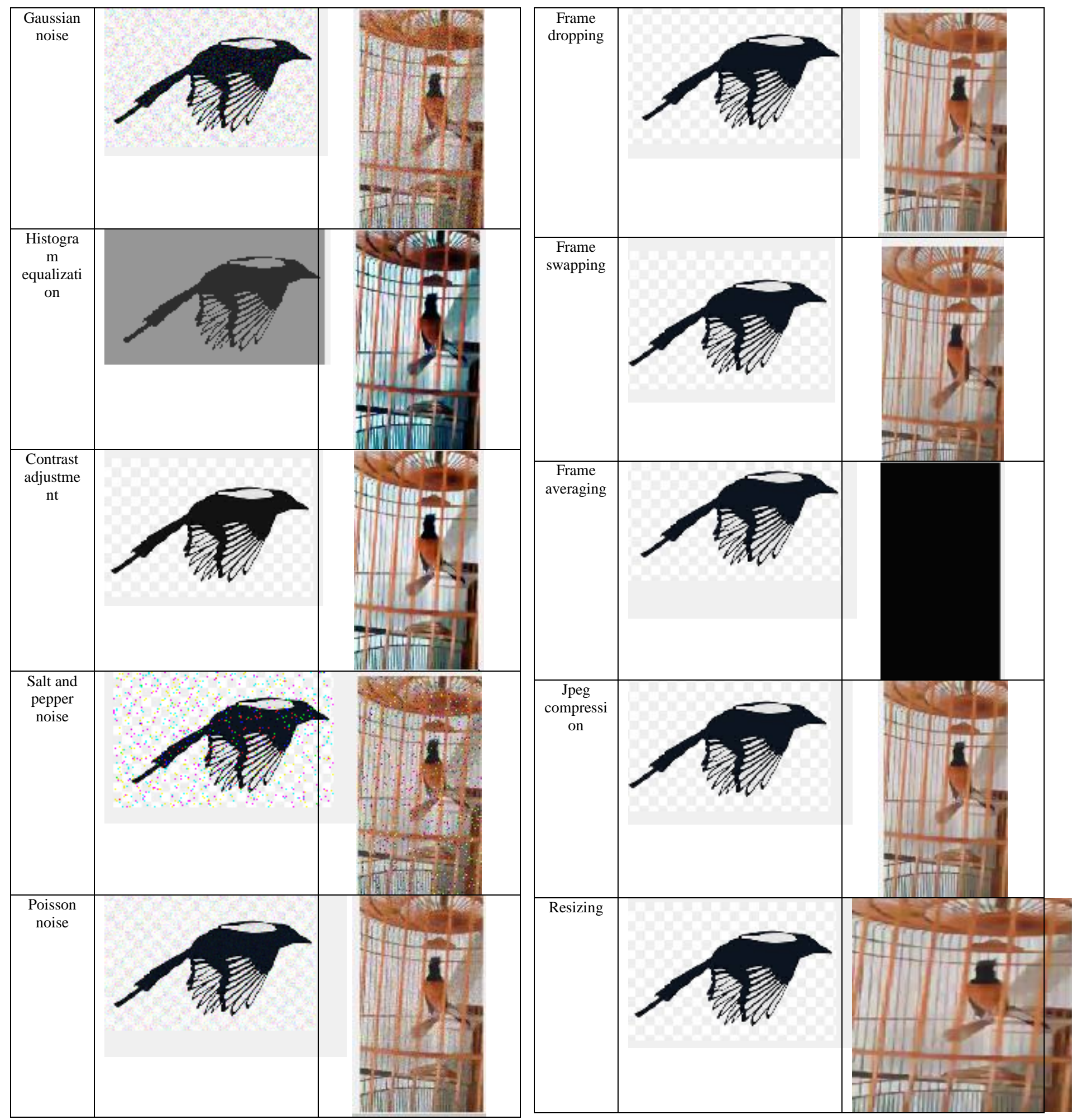


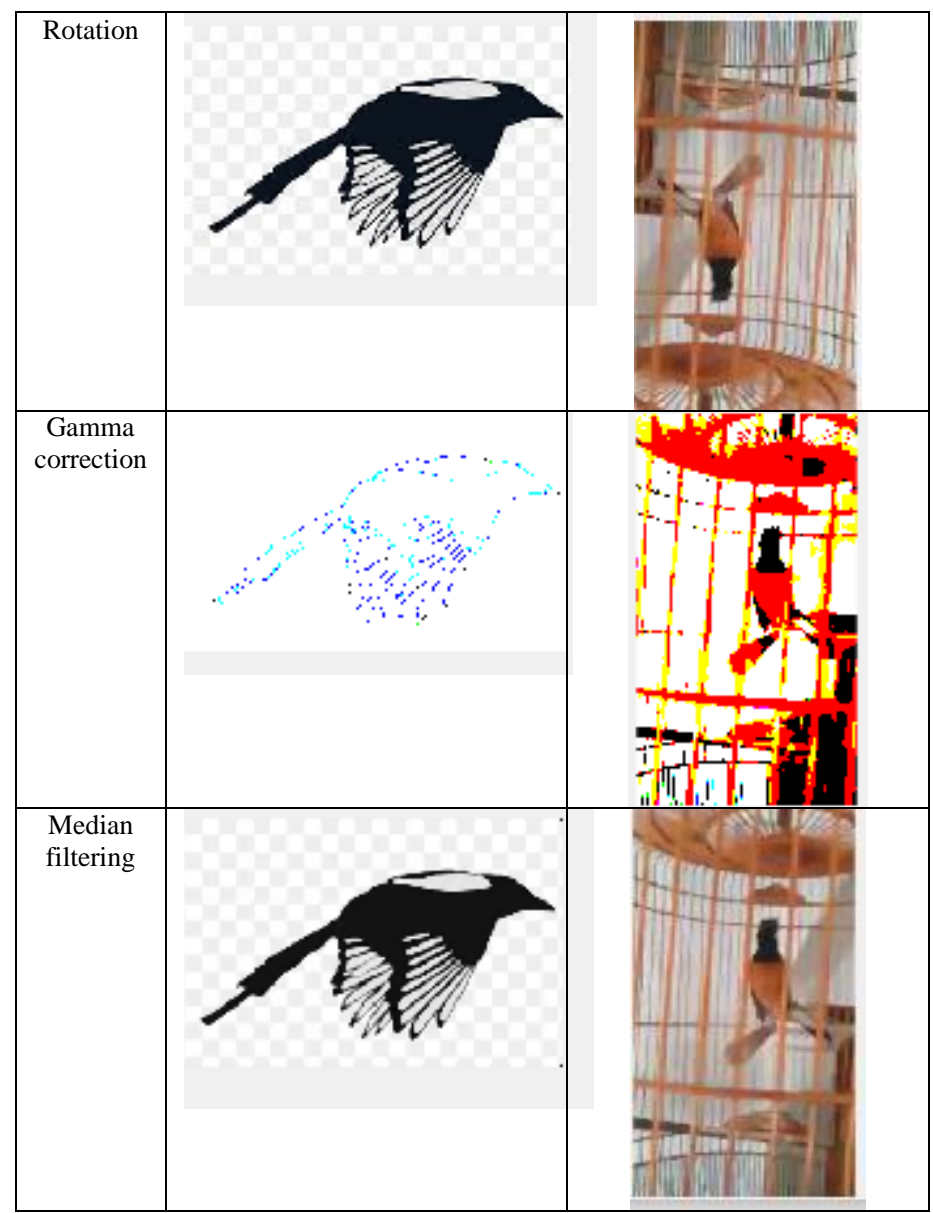

The NC value resulted from the robustness experiment through DFT method toward several attacks is shown in the following Table 8.

TABLE 8. RESULT OF ROBUSTNESS TEST THROUGH DFT METHOD

USING NC

\begin{tabular}{|c|c|}
\hline Types of Attacks & Value of Normalized Correction (NC) \\
\hline Speckle noise & 0,71039 \\
\hline Gaussian noise & 0,70341 \\
\hline Histogram equalization & 0,74907 \\
\hline Contrast adjustment & 0,71176 \\
\hline Salt and pepper noise & 0,76082 \\
\hline Poisson noise & 0,75585 \\
\hline Frame dropping & 0,73329 \\
\hline Frame swapping & 0,78178 \\
\hline Frame averaging & 0,71653 \\
\hline Jpeg compression & 0,79964 \\
\hline Resizing & 0,71289 \\
\hline Rotation & 0,7833 \\
\hline Gamma correction & 0,73832 \\
\hline Median filtering & 0,77914 \\
\hline
\end{tabular}

Table 8 , overall, the NC value is 0,745442 in avarage. It means that the result of extraction is similiar to the original one. In other word, through the DWT method, all of the watermarks can be well extracted though the attacks are delivered to them.

TABLE 9. RESULT OF WATERMARK EXTRACTION AND VIDEO FRAME AFTER ATTACKS DELIVERING

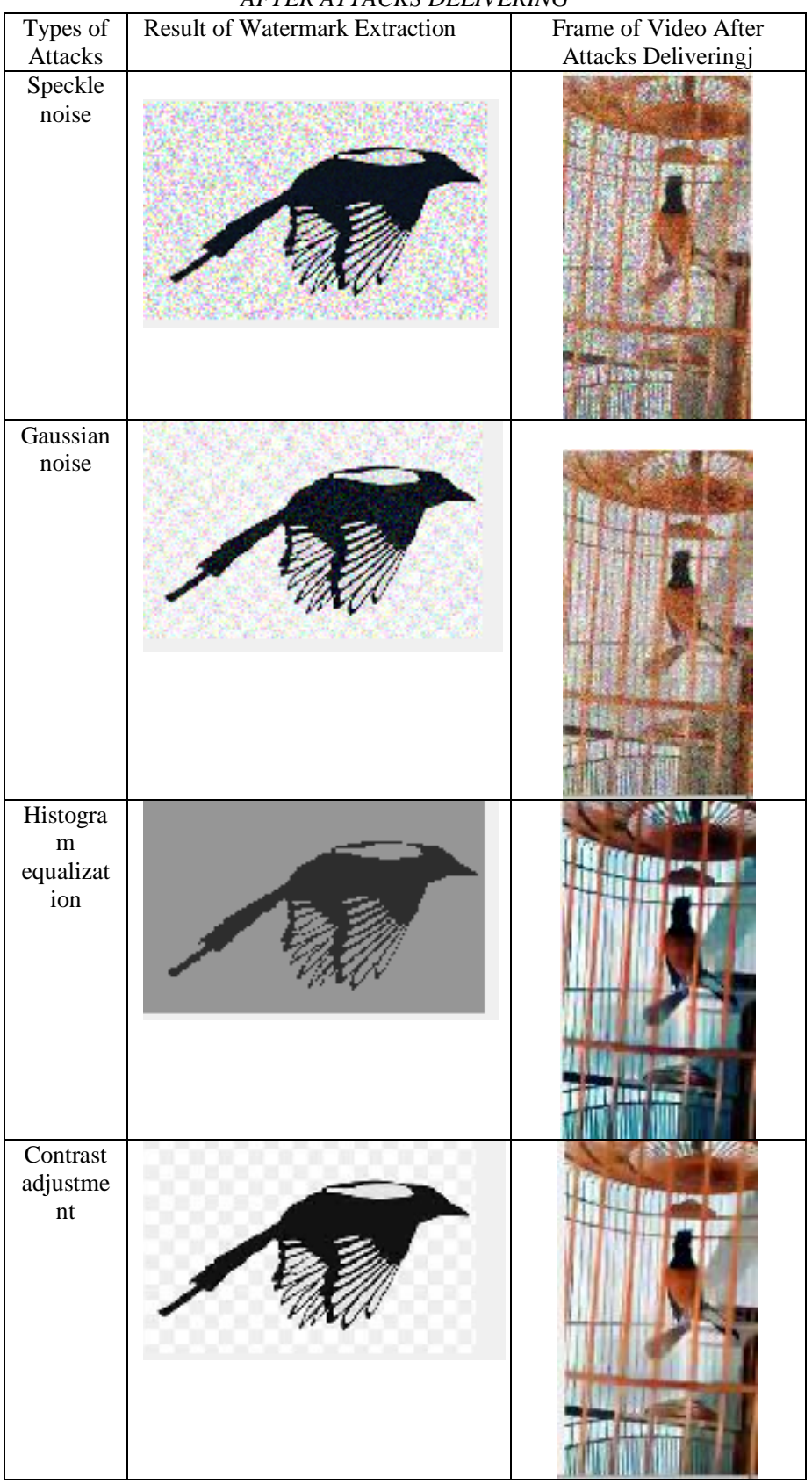



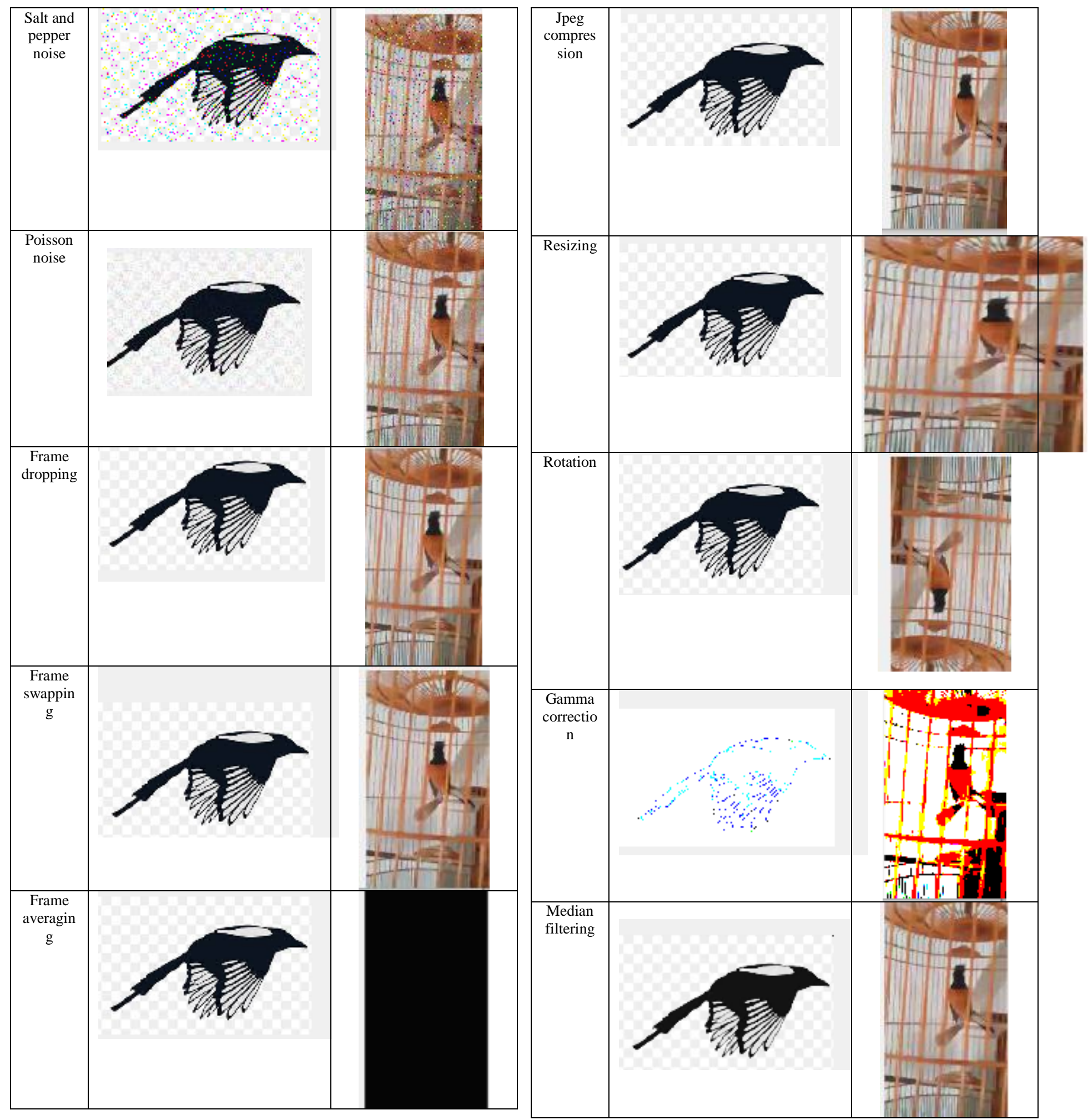


\section{CONCLUSION}

Based on the experiment conducted in this research, it can be concluded that:

1) From the point of imperceptibility, DWT method results PSNR value at 45, $62435 \mathrm{~dB}$, DCT method results PSNR value at 45,89422 $\mathrm{dB}$, and DFT method results PSNR value at $45,77747 \mathrm{~dB}$. The PSNR mean from these three methods is $45,76535 \mathrm{~dB}$. It means that the inserted-watermark video appears similiar to the intercalated one. Thus, from the experiment, it can be sum up that the implemented DWT, DCT, and DFT method show that the quality of watermarked video still in good quality. It means that it is reasonable and meets the imperceptibility.

2) From the point of robustness, the NC mean of DCT method is 0,63974 , DCT method is 0,755839 , and DFT method is 0,745442 . It tells that the result of watermark extraction from these three methods is the same as the original watermark. In other word, all of the watermarks on these three methods can be well extracted though the attack are delivered to them.

3) From the level of imperceptibility and robustness test on DWT, DCT, AND DFT method, it can be said that DCT method is better than DWT and DFT method because it gets a high value on PSNR and NC.

\section{REFERENCES}

[1] R. Agustina and R. A. Asmara, "Penyisipan Watermark Menggunakan Metode Discrete Cosine Transform Pada Citra Digital, ”Jurnal Informatika Polinema, vol. 2, no. 1, pp. 29-34, 2015.

[2] S. Bhargavi Latha, D. Venkata Reddy, and A. Damodaram, "Digital Video Watermarking Using DWT and Singular Values, "ACM International Conference Proceeding Series, vol. 04-05, 2016.

[3] N. Pohan, R. Saragih, and R. Rahim, "Invisible Watermarking Audio Digital with Discrete Cosine Transform, "International Journal Science Research Science Technology., vol. 3, no. 1, pp. 21-25, 2017.

[4] D. Pradhan, "Implementation of Invisible Digital Watermarking Technique for Copyright Protection using DWT-SVD and DCT,
"International Journal Advertisement Engineering Reserach Science, vol. 4, no. 7, pp. 63-69, 2017.

[5] P. M. Sawant, "Digital Watermarking System for Video Authentication," vol. 7, no. 4, pp. 193-197, 2018.

[6] S. R. Febriani and D. C. Irawati, "Implementasi Digital Watermarking ,"Jurnal Informatika dan Komputer, vol. 21, no. 3, pp. 8-18, 2016

[7] L. Rajab, T. Al-Khatib, and A. Al-Haj, "A Blind DWT-SCHUR Based Digital Video Watermarking Technique, "Jurnal Software Engineering Application, vol. 8, pp. 224-233, 2015.

[8] M. M. Ibrahim, N. S. Abdel Kader, and M. Zorkany, "Video Multiple Watermarking Technique Based on Image Interlacing Using DWT ," Science World Journal, 2014.

[9] S. F. Abdulla and S. Anjaneyulu, "A Hybrid DWT-SVD Method for Digital Video Watermarking Using Random Frame Selection, "International Journal Engineering Science, vol. 6, no. 6, pp. 43-48, 2016.

[10] Syamsuryadi and I. Aqil, "Watermarking Video Menggunakan Transformasi Wavelet Diskrit, ” Jurnal Ilmu Informatika Global, vol. 9, pp. 90-94, 2018.

[11] Y. Ariyanto, R. Ardiansyah, and B. Paris, "Steganografi Menggunakan Metode Discrete Fourier Transform (DFT), "Jurnal Informatika Polinema, vol. 4, no. 2, pp. 87-92, 2018.

[12] R. Nainggolan, E. Suhartono, and I. Safitri, "Implementasi dan Analisis Video Watermarking Berbasis DWT-DCT-SS dengan Watermark Terkompres Compressive Sensing, "E-Proceeding Engineering, vol. 6, no. 3, pp. 10263-10277, 2019.

[13] A. Agarwal, R. Bhadana, and S. Chavan, "A Robust Digital Watermarking Using DWT and DCT, "International Journal Computer Science Information Technology, vol. 2, no. 4, pp. 17111716, 2011

[14] M. Shinde, S. Todkar, P. Ubale, and R. . Kedar, "A Block Based Novel Digital Video Watermarking Scheme Using DCT, "International Journal Research Applied Science Engineering Technology, vol. 3, no. 5, pp. 345-349, 2015.

[15] S. A. Al-Taweel, P. Sumari, S. A. K. Alomari, and A. J. Husain, "Digital Video Watermarking in The Discrete Cosine Transform Domain, "Journal Computer Science, vol. 5, no. 8, pp. 536-543, 2009. 